\title{
A Broader View of Perirhinal Function: From Recognition Memory to Fluency-Based Decisions
}

\author{
Ilana T. Z. Dew and Roberto Cabeza \\ Center for Cognitive Neuroscience, Duke University, Durham, North Carolina 27708
}

\begin{abstract}
Although it is well established that the perirhinal cortex (PRC) makes an important contribution to recognition memory, the specific nature of this contribution remains uncertain. The finding that PRC activity is reduced for old compared with new items is typically attributed to the recovery of a long-term memory (LTM) signal. However, because old items are processed more easily or fluently than new items, reduced PRC activity could reflect increased fluency rather than LTM retrieval per se. We tested this hypothesis in humans using fMRI and a well-validated method to manipulate fluency: the masked priming paradigm. Some words during an old-new recognition test were preceded by conceptually related words (primes) that were subliminally presented (masked). The behavioral results replicated previous findings using this paradigm, whereby the fluency manipulation increased "oldness" responses to both old and new items. The fMRI analyses yielded two main sets of results. First, in the case of new items, which are independent from LTM retrieval, masked priming reduced PRC activity and predicted behavioral misattribution of fluency to oldness. Second, in the case of old items, the same PRC region showing fluency-related reductions for new items also contributed to "old" responding to old items. Individual differences in PRC attenuation also predicted oldness ratings to old items, and fluency modulated PRC connectivity with other brain regions associated with processing oldness signals, including visual cortex and right lateral prefrontal cortex. These results support a broader view in which the PRC serves a function more general than memory.
\end{abstract}

\section{Introduction}

The most basic form of declarative memory is recognition memory, the ability to determine whether a stimulus in the present has been encountered previously. A vast body of research has associated recognition memory with the medial temporal lobe region known as the perirhinal cortex (PRC; Brown and Aggleton, 2001; Eichenbaum et al., 2007). PRC lesions impair recognition memory (Meunier et al., 1993; Suzuki et al., 1993; Mumby and Pinel, 1994; Clark and Squire, 2010), and PRC neurons show attenuated firing for previously encountered relative to new stimuli, a phenomenon known as repetition suppression (Desimone, 1996; Brown and Xiang, 1998). Consistent with repetition suppression, functional neuroimaging studies in humans have found greater PRC activity for new than old stimuli (Henson et al., 2003; Montaldi et al., 2006) and gradual PRC decreases from "definitely new" to "definitely old" ratings (Gonsalves et al., 2005; Daselaar et al., 2006).

The standard model of PRC contributions to recognition memory is that the retrieval of long-term memory (LTM) traces is associated with decreased PRC activity and, in turn, increased "old" responses on memory tests. One limitation of this model is

Received April 2, 2013; revised July 22, 2013; accepted Aug. 1, 2013.

Author contributions: I.T.Z.D. and R.C. designed research; I.T.Z.D. performed research; I.T.Z.D. analyzed data; I.T.Z.D. and R.C. wrote the paper.

This work was supported by the National Institute on Aging Grant AG19731 (R.C.) and Fellowship F32AG038298 (I.T.Z.D.). We thank K. Eklund for help in data analyses.

Correspondence should be addressed to llana T. Z. Dew, Center for Cognitive Neuroscience, Box 90999, Duke University, Durham, NC 27708. E-mail: ilana.dew@duke.edu.

DOI:10.1523/JNEUROSCI.1413-13.2013

Copyright $\odot 2013$ the authors $\quad 0270-6474 / 13 / 3314466-09 \$ 15.00 / 0$ that it cannot explain manipulations that increase "old" responding independently of LTM. For example, new stimuli that are presented with higher visual clarity are more likely to be judged "old" (Whittlesea et al., 1990). Additionally, "old" responding increases for recognition items that are preceded by subliminally presented (masked) primes that are identical or semantically related to the corresponding item (Jacoby and Whitehouse, 1989; Rajaram and Geraci, 2000; Whittlesea and Williams, 2001). These effects are assumed to reflect fluency (Jacoby and Dallas, 1981; Yonelinas, 2002), the ease with which incoming information is processed. Recognition items are made easier to process, and this relative increase in fluency is misinterpreted as evidence that the item has been encountered previously (Jacoby and Whitehouse, 1989). These findings suggest the intriguing possibility that PRC attenuations during old responses could reflect increased fluency rather than memory retrieval per se. During recognition tests, old items elicit greater LTM retrieval than new items. However, old items are easier to process, so they also elicit greater fluency than new items. Thus, reduced PRC activity for old items could reflect an increase in fluency that is systematically confounded with oldness.

We investigated this hypothesis using a well-validated technique for manipulating fluency, the masked priming paradigm (Jacoby and Whitehouse, 1989; Rajaram and Geraci, 2000; see Fig. 1). The first goal was to investigate whether a fluency manipulation that increases "old" responses would reduce PRC activity independently of objective LTM retrieval (i.e., on unstudied items). The second goal was to explore whether the same PRC region showing fluency-related reductions for new items would contribute to "old" responding to old items. Within this second 
goal, we first assessed whether individual differences in PRC attenuation would modulate oldness rating and then investigated whether fluency would affect functional connectivity between PRC and other regions associated with processing oldness signals, particularly right lateral prefrontal cortex (PFC; Henson et al., 1999; Dobbins et al., 2003).

\section{Materials and Methods}

Participants. Data were analyzed from 14 participants (nine females; $19-27$ years old; mean \pm SD age, $23 \pm 3.0$ years; mean \pm SD education, $15.0 \pm 1.7$ years). Participants were right-handed, native English speakers with no history of neurological or psychiatric disorders and provided informed consent in accordance with rules established by the Institutional Review Board of Duke University Medical Center. Seven additional participants were excluded as a result of scanner error or failure to complete the experiment, and two were excluded as a result of behavioral performance [one because of an insufficient number of false-alarm responses to model in fMRI analysis (less than five) and one because of an outlying response bias score $(c)>2$ SDs above the mean].

Design and materials. We used the masked priming paradigm, one of the most reliable techniques for manipulating fluency in the behavioral memory literature (Jacoby and Whitehouse, 1989; Rajaram and Geraci, 2000). Stimuli included 476 English words designated as items (e.g., fish, rope; mean of 3-11 letters; word frequency, 74; Kucera and Francis, 1967). For each item, a fluent prime was created such that it was semantically related to the item (e.g., bait, knot) according to free-association norms (mean \pm SD forward association strength, $0.41 \pm 0.18$; Nelson et al., 2004). An additional 476 words were assigned as unrelated primes for the control condition (e.g., taxi, goal), with no apparent association and no listed forward or backward association as per the norms. The scanning session included other conditions that are not relevant to current goals. Across all stimuli, no primes or items overlapped.

Encoding included 238 items. Recognition included the 238 old items plus 238 new items, divided into 63 each of old and new fluent trials and 112 each of old and new control trials. To control for item effects, stimuli were randomly ordered and assigned to condition uniquely for every subject. Lists were divided into seven, 8:14 min runs. A blind search algorithm determined the order of events within each run and the duration of each jittered fixation (average, $2000 \mathrm{~ms}$ ).

Procedure. Before scanning, participants incidentally encoded words via living/nonliving judgments (2000 ms each). During scanning, participants completed the old/new recognition test (Fig. 1). The critical manipulation occurred before each recognition item when a masked prime was presented. Each recognition trial began with the prime or $40 \mathrm{~ms}$, which was immediately backward masked by the recognition item for $500 \mathrm{~ms}$. The item was replaced by a row of Xs for $4500 \mathrm{~ms}$. During this period, participants had $3000 \mathrm{~ms}$ to the old/new recognition judgment and $1500 \mathrm{~ms}$ to make the low/medium/high confidence rating. These two phases were indicated by the response options, which were displayed at the bottom of the screen.

fMRI methods and procedures. Images were collected using a $3 \mathrm{~T}$ GE Healthcare scanner with standard head coil. Anatomical image acquisition involved a T1-weighted three-dimensional localizer series, with 96 axial slices parallel to the anterior-posterior commissure plane (FOV, 24; voxel dimensions, $0.9 \times 0.9 \times 1.9 \mathrm{~mm}^{2}$ ). Functional images were acquired using a $\mathrm{T} 2{ }^{*}$-weighted gradient-recalled inward spiral pulse sequence (Glover and Law, 2001) sensitive to the blood oxygenation leveldependent signal (TR, 2000 ms; TE, 31 ms; FOV, 24; 34 oblique slices with voxel dimension $3.75 \times 3.75 \times 3.8 \mathrm{~mm}^{2}$ ). Three volumes were acquired and discarded at the start of each run.

Preprocessing and statistical analyses were performed using Statistical Parametric Mapping software (SPM8; Wellcome Department of Cognitive Neurology, London, UK). Images were corrected for offsets in the time of acquisition by resampling all slices to match the first slice, which was used as a reference slice of the volume. Images were realigned to correct for motion across runs and spatially normalized to an EPI template, using both a 12-parameter affine transformation and a nonlinear

\section{Scanned Behavioral Paradigm}

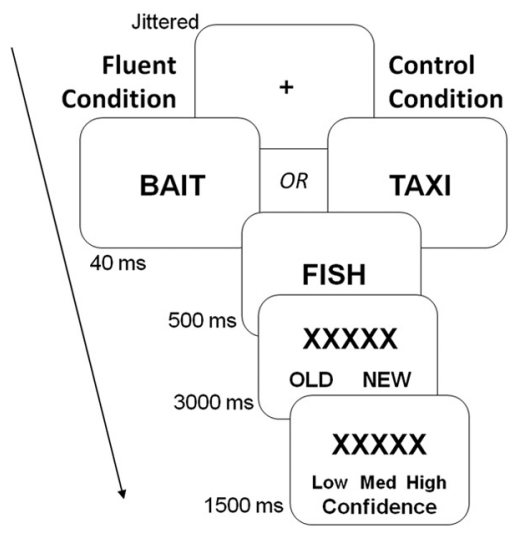

Figure 1. Experimental paradigm. Before scanning, participants incidentally encoded a list of words by making semantic judgments (living/nonliving). During scanning, participants viewed old and new words and responded to each one with an old/new decision, followed by a confidence rating. The critical manipulation occurred before each recognition item when a 40 ms masked prime was presented. In the fluent condition, the masked prime was semantically related to the recognition item (e.g., bait, fish), making this item easier to process, whereas in the control condition, the masked prime was unrelated to the recognition item (e.g., taxi, fish).

transformation using cosine basis functions. The images were spatially smoothed with an $8 \mathrm{~mm}$ full-width half-maximum Gaussian kernel.

Statistical analyses. Volumes were examined as temporally correlated time series. Events were modeled as stick functions representing trial onsets, convolved with a canonical hemodynamic response function using the general linear model for event-related designs. Trial types from each condition were segregated based on accuracy and response (e.g., fluent hits) and were used to model linear contrasts at the fixed-effects level against implicit baseline, after which the second-level analysis used subjects as a random effect. Unless noted otherwise, a threshold of $p<$ 0.001 uncorrected, cluster extent $k=8$, was used for group-level contrasts. Regions-of-interest (ROIs) analyses were performed by extracting the mean $\beta$ value from all significantly active voxels within the functional cluster of interest.

To assess within-subjects (trial-to-trial) correlations between neural activity and behavioral response, each trial was modeled as a separate event, yielding different $\beta$ values for each trial and each subject in the seed cluster of interest (Rissman et al., 2004). For each individual, these $\beta$ values were entered into separate regression analyses, using behavioral response on each trial as the dependent variable. To assess group effects, the resulting mean standardized regression coefficients were submitted to a one-sample $t$ test at $p<0.05$.

To assess functional connectivity, we used the PRC as a seed region and examined correlations between the time series activity of the seed region with all other voxels in the brain. A cube was built using all the voxels directly adjacent to the peak coordinate within the functional PRC cluster identified by the first ANOVA model. A correlation map was created for each condition that displayed the correlation magnitude between every voxel and the PRC seed region over time. Maps were subsequently entered into SPM to identify brain regions showing differential connectivity as a function of experimental condition.

All activations are presented according to neurological convention. In the figures, statistically significant activity is projected onto a singlesubject T1 structural image template. Brodmann area (BA) and gyral localizations of activations were determined using the Wake Forest University PickAtlas and the Talaraich Client (http://www.talairach. org/client.html).

\section{Results}

\section{Behavioral results}

The effect of fluency was measured by comparing the proportion of "old" responses for fluent versus control trials when the words 
were objectively old or new (hits or false alarms; Fig. 2A). Fluency increased old responding for both old and new trials, with both the hit rate $\left(t_{(13)}=2.29, p=0.039\right.$, $d=0.65)$ and false-alarm rate $\left(t_{(13)}=\right.$ 2.64, $p=0.020, d=0.89)$ significantly greater for fluent than control trials (Fig. $2 A, B)$. Accuracy (hits - false alarms) was significantly higher than chance for both fluent (mean, 0.42; $t_{(13)}=9.01, p<$ $0.0001, d=5.08$ ) and control (mean, 0.45; $\left.t_{(13)}=13.21, p<0.0001, d=4.96\right)$ trials but equivalent between conditions $\left(t_{(13)}\right.$ $=0.52, p=0.61$ ).

In signal-detection models, a manipulation that affects both hits and false alarms without altering accuracy suggests a change in response bias rather than sensitivity to the memory signal (Macmillan and Creelman, 2005). Sensitivity was measured as $d^{\prime}$ (the difference between $z$-transformed hits and false alarms) and bias to respond "old" or "new" as $c(<0$, tendency to respond "old"; $>0$, tendency to respond "new"). $d$ ' did not differ between fluent and control conditions $\left(t_{(13)}\right.$ $=0.32, p=0.75)$. Critically, $c$ was significantly smaller $\left(t_{(13)}=3.18, p=0.007\right.$, $d=1.1)$ in the fluent $(c=-0.04)$ than the control ( $c=0.25$ ) condition, confirming a stronger bias to respond "old" in the former relative to the latter. Thus, participants were more likely to classify words preceded by a related prime as "old," yet because they showed this trend for both objectively old and new words, the effect was observed as a change in bias rather than sensitivity. Of note, in some previous behavioral studies, the effect of fluency on recognition responses has been more robust for new than old items (Jacoby and Whitehouse, 1989; Whittlesea and Williams, 2001; Westerman, 2008). However, these findings are mixed in the literature, and the current data are consistent with several previous reports wherein fluency equivalently increased oldness responses to both old and new trials (Rajaram and Geraci, 2000; Kurilla and Westerman, 2008; Woollams et al., 2008).

Next, we used the three confidence levels each for old and new response trials to construct a "perceived oldness" scale that ranged from 1 (high-confidence "new") to 6 (high-confidence "old"). Fluency increased oldness ratings for both old words and new words (Fig. 2C). A 2 (fluency: fluent vs control) $\times 2$ (item type: old vs new) ANOVA yielded significant main effects of fluency $\left(F_{(1,13)}=16.82, p=0.001\right.$, partial $\left.\eta^{2}=0.56\right)$ and item type $\left(F_{(1,13)}=94.00, p<0.0001\right.$, partial $\left.\eta^{2}=0.88\right)$ with no interaction $(F<1, p=0.47)$. Together, these behavioral analyses replicate previous findings (Rajaram and Geraci, 2000) showing that fluency increases oldness responses to both old and new items.

Importantly, although masked conceptual priming has been shown previously to selectively increase familiarity (Rajaram and

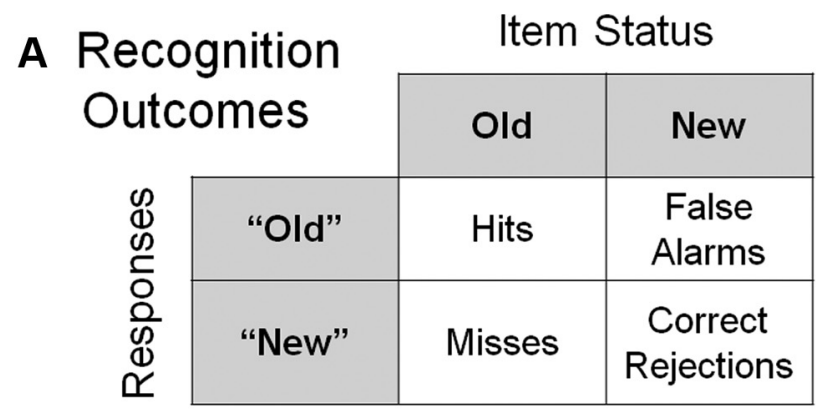

\section{B Hits, False Alarms, \& Accuracy}
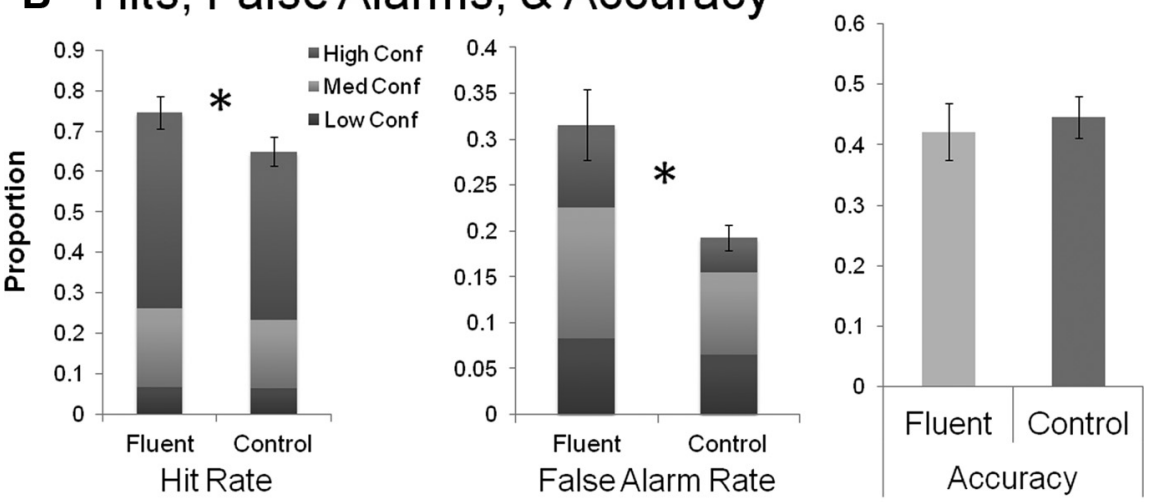

C Oldness Ratings

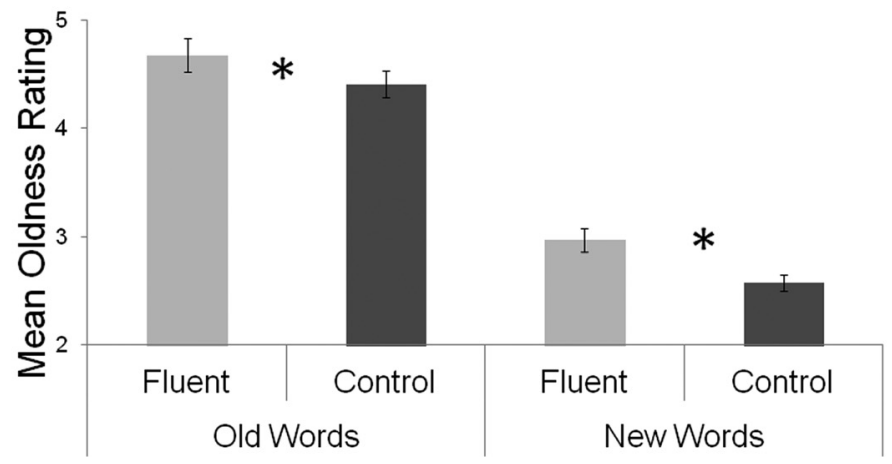

Figure 2. Behavioral results. $\boldsymbol{A}$, Behavioral results measured the proportion of old responses to old items, or hits, and old esponses to new items, or false alarms. $\boldsymbol{B}$, Both the hit rate and false-alarm rate were significantly greater for fluent than contro ged from 1 (high-confidence "new") to 6 (high-confidence "old). Fluency increased oldness ratings equivalently for both old and new words. Error bars indicate standard error. ${ }^{*} p<0.05$.

Geraci, 2000), two recent studies (Taylor and Henson, 2012; Taylor et al., 2013) have argued that conceptual fluency can in some circumstances increase recollection-based responses. In the current study, an effect of fluency on recollection would be indicated by a disproportionate increase in high- over lowerconfidence hits. To determine whether the fluency manipulation affected the distribution of confidence judgments for "old" responses, a $2 \times 2 \times 3$ ANOVA was performed, with factors of fluency condition (fluent, control), item type (old, new), and confidence (high, medium, low). Only "old" responses (hits and false alarms) were included. Predictably, there was a main effect of item type, with a higher proportion of "old" responses to old versus new items $\left(F_{(1,13)}=171.0, p<0.0001\right)$. There was also a main effect of fluency, with more "old" responses to fluent versus control trials $\left(F_{(1,13)}=13.6, p=0.003\right)$ and a significant effect of 
Table 1. Successful recognition memory (hits $>$ correct rejections)

\begin{tabular}{|c|c|c|c|c|c|c|c|}
\hline \multirow[b]{2}{*}{ Region } & \multirow[b]{2}{*}{$\mathrm{H}$} & \multirow[b]{2}{*}{ BA } & \multirow[b]{2}{*}{ Voxels } & \multicolumn{3}{|l|}{ MNI } & \multirow[b]{2}{*}{$t$ value } \\
\hline & & & & $x$ & $y$ & $z$ & \\
\hline Insula & $\mathrm{L}$ & 13 & 86 & -31 & 27 & 7 & 7.49 \\
\hline Inferior frontal gyrus & $\mathrm{L}$ & 45 & & -38 & 27 & 11 & 7.15 \\
\hline Middle frontal gyrus & $\mathrm{L}$ & 11 & & -23 & 27 & -12 & 4.68 \\
\hline Parahippocampal gyrus & $\mathrm{R}$ & 36 & 12 & 37 & -30 & -20 & 7.29 \\
\hline Lingual gyrus & $\mathrm{R}$ & 18 & 50 & 18 & -71 & 3 & 7.24 \\
\hline Precuneus & $\mathrm{L}$ & 31 & 109 & -20 & -60 & 30 & 6.66 \\
\hline Superior parietal lobule & $\mathrm{L}$ & 7 & & -12 & -67 & 53 & 5.55 \\
\hline Cingulate gyrus & $\mathrm{R}$ & 23 & 113 & 7 & -18 & 26 & 6.05 \\
\hline Cingulate gyrus & $\mathrm{R}$ & 23 & & -1 & -26 & 34 & 5.58 \\
\hline Cingulate gyrus & $\mathrm{R}$ & 31 & & 3 & -33 & 41 & 4.73 \\
\hline Fusiform gyrus & $\mathrm{L}$ & 20 & 15 & -46 & -26 & -20 & 6.01 \\
\hline Inferior frontal gyrus & $\mathrm{R}$ & 47 & 38 & 18 & 12 & -23 & 5.7 \\
\hline Inferior frontal gyrus & $\mathrm{R}$ & 47 & & 29 & 31 & -12 & 5.49 \\
\hline Inferior frontal gyrus & $\mathrm{R}$ & 47 & & 26 & 16 & -20 & 4.75 \\
\hline Precuneus & $\mathrm{R}$ & 31 & 36 & 18 & -63 & 34 & 5.44 \\
\hline Hippocampus & $\mathrm{L}$ & & 5 & -23 & -26 & -12 & 5.19 \\
\hline Postcentral gyrus & $\mathrm{R}$ & 3 & 16 & 52 & -15 & 56 & 5.01 \\
\hline Thalamus & $\mathrm{L}$ & & 13 & -12 & -30 & 3 & 4.7 \\
\hline Anterior cingulate & $\mathrm{R}$ & 32 & 28 & -1 & 42 & 11 & 4.66 \\
\hline Anterior cingulate & $\mathrm{L}$ & 32 & & -5 & 38 & 18 & 4.21 \\
\hline Inferior parietal lobule & $\mathrm{L}$ & 39 & 5 & -35 & -63 & 45 & 4.5 \\
\hline Middle temporal gyrus & $\mathrm{L}$ & 22 & 10 & -53 & -48 & -4 & 4.49 \\
\hline Anterior cingulate & $\mathrm{R}$ & 24 & 11 & -1 & 27 & 30 & 4.47 \\
\hline Cingulate gyrus & $\mathrm{L}$ & 32 & & -8 & 23 & 37 & 4.46 \\
\hline Anterior cingulate & $\mathrm{R}$ & 32 & 7 & 11 & 34 & 22 & 4.28 \\
\hline
\end{tabular}

H, Hemisphere; L, left; R, right; MNI, Montreal Neurological Institute.

confidence $\left(F_{(1,13)}=22.4, p<0.0001\right)$, with a higher proportion of high-confidence hits than any other category. The only significant interaction was item type $\times$ confidence $\left(F_{(1,13)}=47.4, p<\right.$ 0.0001 ), such that there were more high- than medium- and low-confidence hits but not more high- than medium- or lowconfidence false alarms. No other two- or three-way interaction was significant (all $p$ values $>0.05$ ), indicating that the fluency manipulation did not influence the distribution of confidence responses. Given equivalent distribution of confidence responses as a function of fluency, the current data are more consistent with the view that conceptual fluency influences familiarity. However, it should be noted that this study did not instruct participants to endorse recollection- or familiarity-specific responses. Furthermore, we used a set of prime-target pairings that does not distinguish between forms of relatedness, which may account for differences between this study and those that have been shown to affect recollection (Taylor and Henson, 2012; Taylor et al., 2013).

Finally, reaction times (RTs) were entered into a $2 \times 2 \times 2$ ANOVA with factors of item type (old, new), response ("old," "new"), and fluency (fluent, control). There was a main effect of item type, with faster RTs to old versus new trials $\left(F_{(1,13)}=14.0\right.$, $p=0.002)$, and a main effect of fluency, with faster RTs to fluent versus control trials $\left(F_{(1,13)}=5.77, p=0.032\right)$. However, neither the main effect of response $(p=0.17)$ nor the fluency $\times$ response interaction ( $p=0.76)$ were significant; thus, RTs were not related to oldness judgments.

\section{Fluency-related PRC reductions during new items}

fMRI analyses began with verifying that recognition memory was associated with regions typically active during successful retrieval. Greater activity during hits compared with correct rejections was observed in the medial temporal lobe (right posterior parahippocampal gyrus and bilateral hippocampus), right dorsolateral and left anterior PFC (BAs 47 and 11), and left dorsal parietal cortex (BA 7) (Table 1), consistent with a vast body of
Table 2. Prime $\times$ response interaction [fluent (correct rejections $>$ false alarms) $>$ control (correct rejections $>$ false alarms)]

\begin{tabular}{|c|c|c|c|c|c|c|c|}
\hline \multirow[b]{2}{*}{ Region } & \multirow[b]{2}{*}{$\mathrm{H}$} & \multirow[b]{2}{*}{$B A$} & \multirow[b]{2}{*}{ Voxels } & \multicolumn{3}{|l|}{ MNI } & \multirow[b]{2}{*}{$t$ value } \\
\hline & & & & $x$ & $y$ & $z$ & \\
\hline Cuneus & $\mathrm{R}$ & 18 & 93 & 7 & -101 & 18 & 5.18 \\
\hline Precentral gyrus & $\mathrm{R}$ & 4 & 46 & 33 & -22 & 72 & 4.95 \\
\hline Posterior parahippocampal gyrus & $\mathrm{R}$ & 36 & 13 & 18 & -18 & -20 & 4.55 \\
\hline Temporopolar cortex & $\mathrm{L}$ & 38 & 15 & -38 & 12 & -27 & 4.39 \\
\hline Fusiform gyrus & L & 19 & 55 & -23 & -63 & -12 & 4.02 \\
\hline Parahippocampal gyrus & L & 28 & 9 & -23 & -18 & -20 & 3.94 \\
\hline Posterior cingulate & L & 29 & 13 & -12 & -45 & 7 & 3.84 \\
\hline \multirow[t]{2}{*}{ Perirhinal cortex } & $\mathbf{R}$ & 36 & 8 & 37 & -15 & -27 & 3.74 \\
\hline & $\mathbf{R}$ & 35 & & 33 & -26 & -23 & 3.41 \\
\hline Cuneus & $\mathrm{R}$ & 18 & 10 & 22 & -71 & 15 & 3.71 \\
\hline
\end{tabular}

H, Hemisphere; L, left; R, right; MNI, Montreal Neurological Institute. Bold text highlights hypothesized region.

research on the neural basis of recognition memory (Buckner and Wheeler, 2001; Stark and Squire, 2001). The next analysis verified whether, collapsing across fluency condition, PRC activity would be reduced for trials perceived as old relative to new (as in the studies by Gonsalves et al., 2005; Montaldi et al., 2006; Daselaar et al., 2006). Regions were contrasted showing greater activity for all "new" compared with "old" memory responses. This analysis revealed a cluster in right $\operatorname{PRC}(x, y, z=29,-18,-31 ; p<0.002)$.

Subsequently, analyses turned toward the first goal by investigating the possibility that fluency would reduce PRC activity on unstudied items incorrectly called "old" (i.e., independently of LTM retrieval). We investigated this idea with a 2 (fluent vs control) $\times 2$ (correct rejections vs false alarms) ANOVA, searching for regions showing an interaction whereby activity was lower in the fluent condition, particularly for false alarms. In other words, we identified regions showing an activity reduction as a function of fluency rather than as a function of memory retrieval. A right PRC region showed this pattern (Table 2). ROI analysis showed that PRC activity was reduced for fluent false alarms compared with both control false alarms and fluent correct rejections (Fig. $3 A$ ). The effect of fluency was found for false alarms but not for correct rejections possibly because the fluency effect was stronger during the former, contributing to the erroneous "old" judgment. Verifying the localization of this activation, we reran this contrast using a probabilistic map of bilateral PRC (Devlin and Price, 2007) as an anatomical inclusive mask. The right PRC (identical primary peak coordinate) was identified even when restricting the analysis to activations that exceeded a statistical threshold of $p<0.05$ familywise error corrected.

To test whether the PRC cluster showing fluency-related reductions overlapped with the PRC cluster showing standard recognition-related deactivations, the prime $\times$ response interaction was rerun using regions from the previously described recognition contrast (all "new" > "old" memory decisions) as an inclusive mask. Each contrast was entered at a threshold of $p<$ 0.01 to yield an approximate conjoint probability of $p<0.001$, noting that the individual contrasts are not independent. The right PRC was identified in this conjunction analysis $(x, y, z=33$, $-18,-23)$, indicating that the same region indexing standard oldness reductions without deference to the fluency manipulation also indexes fluency-mediated memory misattributions.

To supplement the novel finding identified by the interaction effect, we investigated whether behavioral responses on new items could be predicted by trial-to-trial differences in PRC activity. A logistic regression analysis was performed in which the independent variable was the beta estimate of PRC activity for each new trial and the dependent variable was the corresponding 


\section{A PRC Activity (New Items)}

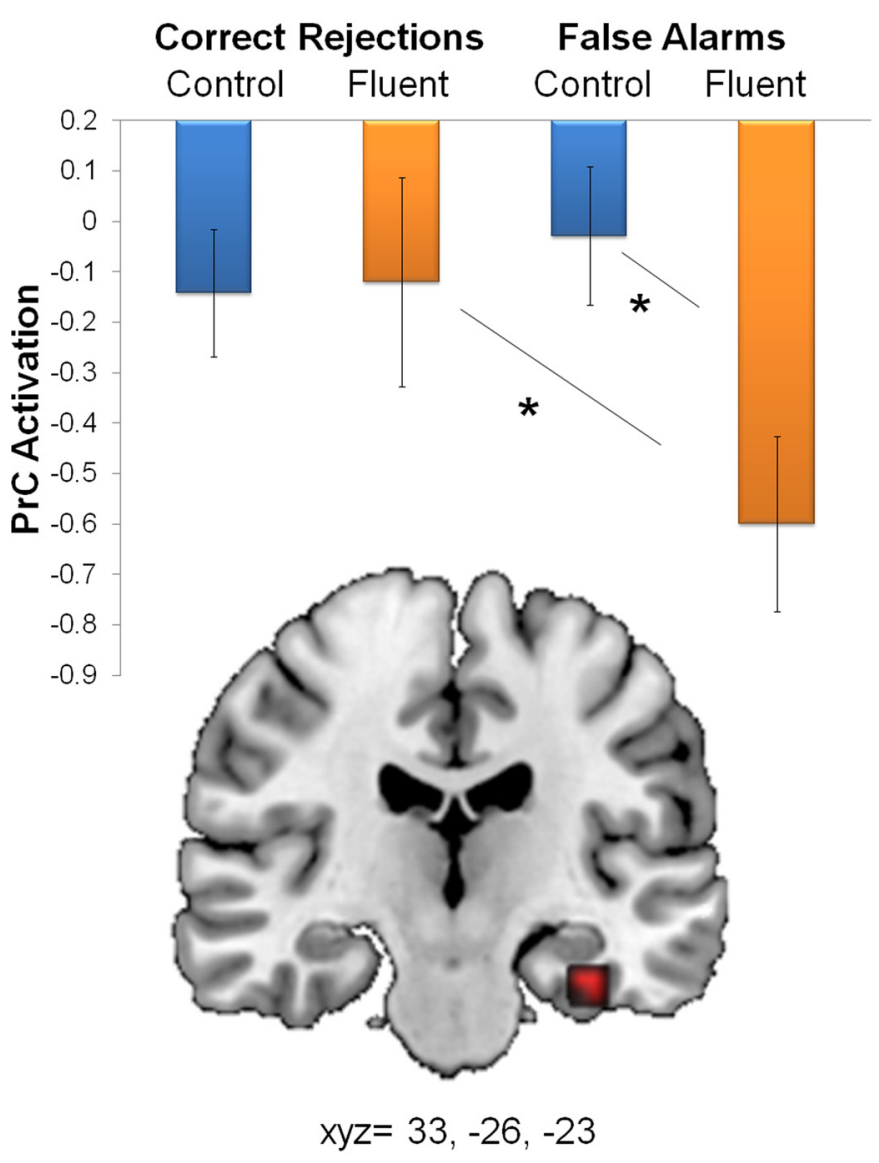

\section{B Activity-Behavior Links (New Items)}

\section{Within-Subjects Logistic Regression}

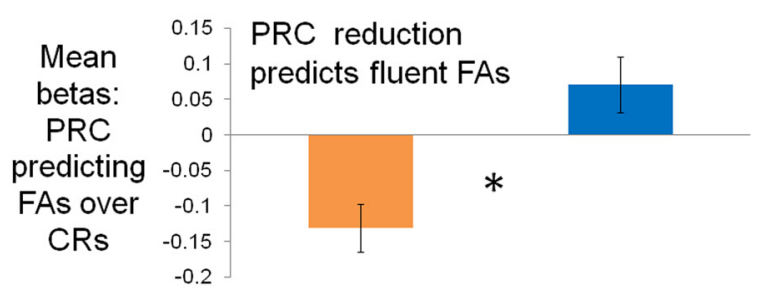

Fluent Control

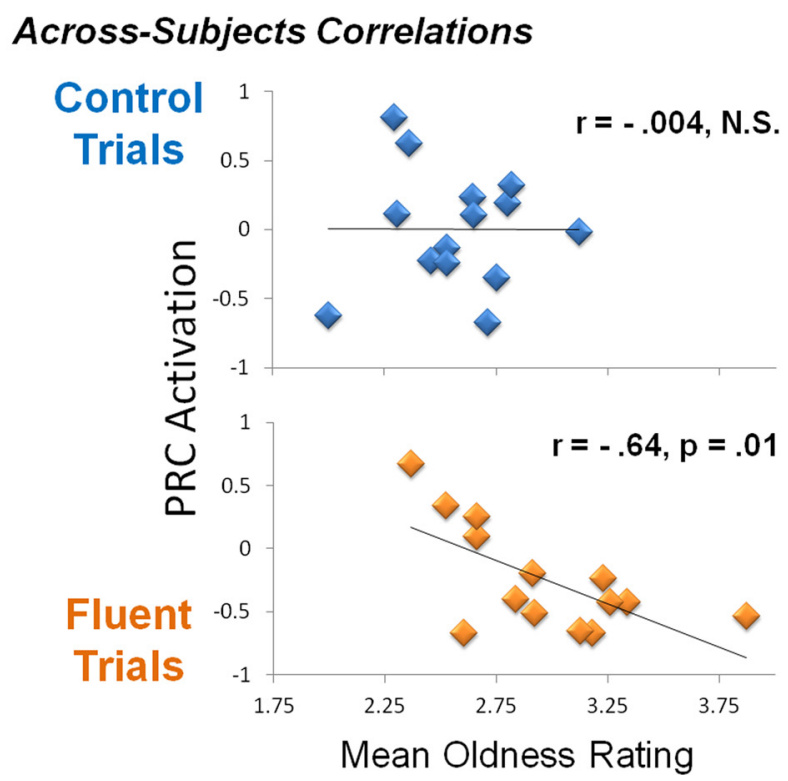

Figure 3. Isolated fluency effect in PRC. The effects of fluency, independently of LTM, were identified using new items that were incorrectly classified as "old." $\boldsymbol{A}$, Neural deactivations in PRC were observed during fluent, but not control, false alarms. This interaction represents the isolated effect of fluency on recognition judgments, removed from the potential contribution of an encoded memory trace. $\boldsymbol{B}$, Individual differences in PRC attenuation were found to modulate the behavioral misattribution, and trial-to-trial variations in PRC activity predicted the likelihood of making an "old" over a "new" response to new trials. These performance-related activity reductions indicate a fine-grained sensitivity of PRC to fluency-specific operations. CR, Correct rejections; FA, false alarms. Error bars indicate standard error. ${ }^{*} p<0.05$.

"old" versus "new" response. PRC activity reductions significantly predicted the likelihood of making a false alarm as opposed to a correct rejection in the fluent $(\beta=-0.13, p=0.003)$ but not control $(\beta=0.07, p=0.12)$ condition on a within-subjects, trial-to-trial basis (Fig. $3 B$, top).

Next we tested the prediction that individual differences in fluency-related PRC attenuation would be associated with behavioral misattributions of oldness. Across participants, PRC activations during fluent trials negatively correlated with mean oldness rating to fluent new trials $\left(r_{(13)}=-0.64, p=0.01\right)$, but PRC activations during control trials did not correlate with mean oldness rating to control new trials $\left(r_{(13)}=-0.004, p=0.99\right)$ (Fig. $3 B$ ). When compared directly (http://quantpsy.org), these correlation coefficients were significantly different from each other ( $p=0.03$ ). Thus, for fluent but not control items, participants with lower PRC activity tended to rate new items as older. Together, the findings strongly suggest a direct link between PRC reductions and "old" recognition decisions derived from fluency, independently from memory.

\section{Fluency-related PRC reductions extend to old items}

The next goal was to assess whether the PRC region shown to be modulated by fluency during new items would contribute to "old" responding to old items. Thus, this analysis focuses on the link between PRC reductions and correct oldness attributions (i.e., hits). We tested the prediction that higher mean oldness rating on old trials would be modulated by individual differences in PRC attenuation. Using the PRC cluster identified by the preceding analysis as a functional ROI, lower PRC activity during hits was associated with an increase in mean oldness rating to old items across participants (Fig. $4 A ; r_{(13)}=-0.56, p=0.038$ ). It is worth noting that this correlation is independent from the previous analysis because true old trials were not modeled in that ANOVA. This finding is consistent with previous evidence linking PRC reductions to perceived oldness (Gonsalves et al., 2005; Daselaar et al., 2006), but the association here was found in the same PRC region in which the fluency manipulation modulated oldness to new items. Thus, whereas previous research has attributed the PRC-oldness link to LTM retrieval, this finding links it to fluency.

The final analysis investigated whether the significant effect of fluency on oldness ratings may reflect not only PRC activity but also its impact on other components of the recognition network, particularly those associated with acontextual recognition (familiarity). To investigate this idea, we tested the prediction that, if 


\section{A Perirhinal Activity during Correct Old Trials}

B Perirhinal Connectivity during Memory Success
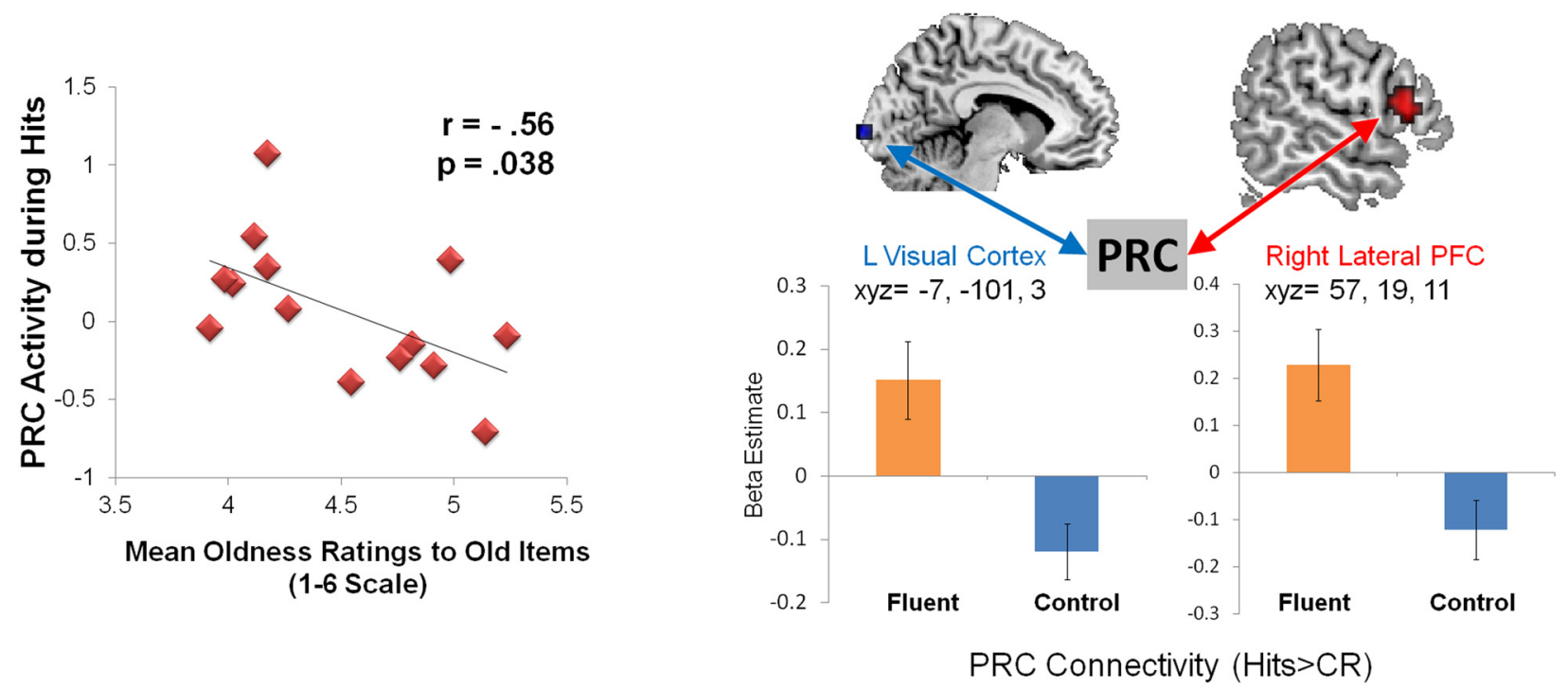

Figure 4. Fluency-relatedPRC reductions extend to old items. $A$, Individual differencesin PRC attenuation predictedmean oldnessrating to old items. $B$, During successful LTM retrieval (hits $>$ correctrejections), perirhinal connectivity with visual cortex and right lateral PFC was stronger during the fluent compared with control condition. CR, Correct rejections. Error bars indicate standard error.

Table 3. Perirhinal connectivity during memory success (fluent $>$ control, hits $>$ correct rejections)

\begin{tabular}{|c|c|c|c|c|c|c|c|}
\hline \multirow[b]{2}{*}{ Region } & \multirow[b]{2}{*}{$\mathrm{H}$} & \multirow[b]{2}{*}{$B A$} & \multirow[b]{2}{*}{ Voxels } & \multicolumn{3}{|l|}{ MNI } & \multirow[b]{2}{*}{$t$ value } \\
\hline & & & & $x$ & $y$ & $z$ & \\
\hline Lateral frontal gyrus & $\mathrm{R}$ & 45 & 20 & 57 & 19 & 11 & 4.00 \\
\hline Cuneus & L & 18 & 6 & -7 & -101 & 3 & 3.65 \\
\hline Fusiform gyrus & $\mathrm{R}$ & 20 & 7 & 42 & -37 & -16 & 3.49 \\
\hline
\end{tabular}

H, Hemisphere; L, left; R, right; MNI, Montreal Neurological Institute.

PRC reductions reflect fluency, then functional connectivity between PRC and familiarity-related regions should be stronger for fluent than control trials. In contrast, if the PRC does not index fluency but rather objective LTM retrieval, then connectivity between PRC and familiarity regions should emerge during accurate retrieval independently of the fluency manipulation. Although the network of brain regions associated with processing familiarity signals has sometimes been variable and hard to interpret, one of the most consistently observed regions is the right lateral PFC (Henson et al., 1999; Dobbins et al., 2003). Using as a seed the functional PRC region from the fluency $\times$ response interaction, perirhinal connectivity maps were entered into SPM to identify brain regions showing an interaction effect, with stronger PRC connectivity during successful LTM in the fluent relative to control condition. For consistency with the standard recognition memory literature (Buckner and Wheeler, 2001; Stark and Squire, 2001), successful LTM was operationalized as hits $>$ CRs. A cluster of significant activation was observed in right lateral PFC at BA 45 $(t=4.00 ; x, y, z=57,19,11)$, as well as left cuneus in visual cortex (BA 18; $t=3.65 ; x, y, z=-7,-101,3$; Table 3 ). As seen in Figure $4 B$, there is a significant positive correlation in the fluent but not control condition, which shows a tendency in the opposite direction. These results indicate that the PRC can contribute to both illusory and veridical recognition decisions via fluency-specific operations.

\section{Discussion}

The PRC typically shows reduced activity for old compared with new items, an effect that is typically attributed to an acontextual LTM signal (Eichenbaum et al., 2007). We investigated the alternative hypothesis that PRC reductions reflect fluency rather than memory. Fluency was manipulated using a masked priming technique that reliably increases the probability of "old" responding independently of LTM retrieval (Jacoby and Whitehouse, 1989; Rajaram and Geraci, 2000).

To investigate the effects of fluency independently of LTM, we first focused on unstudied items. Neural deactivations in PRC were observed during fluent, but not control, new items incorrectly classified as "old" (false alarms) (Fig. $3 A$ ). Supplementing this effect, trial-to-trial variations in PRC activity predicted the likelihood of making an "old" over a "new" response to unstudied trials. As noted previously, the effect of fluency was found for false alarms but not for correct rejections possibly because the fluency effect was stronger during the former, contributing to the erroneous "old" judgment. Individual differences in PRC attenuation across subjects were then found to modulate behavioral misattributions of fluency to oldness (Fig. 3B). We note that, although these correlations are informative, future studies should determine whether PRC activity can vary at the item level across subtle changes in confidence, an analysis for which there were not enough trials in the current data.

The second goal was to investigate whether the PRC region associated with fluency independently of LTM also contributes to old responses to objectively old items. Consistent with this idea, individual differences in PRC attenuation during hits predicted oldness ratings to old items (Fig. $4 A$ ). These performance-related activity reductions indicate a fine-grained sensitivity of the PRC to fluency-specific operations. Finally, PRC activity during successful recognition covaried with activation levels in a region strongly associated with processing heuristic- or familiaritybased memory signals (Nolde et al., 1998; Dobbins et al., 2003), the right lateral PFC (Fig. 4B).

In summary, the results suggest that a neural region overwhelmingly interpreted to index objective LTM retrieval may 
index fluency that occurs incidentally during standard recognition tests. One caveat of the study is the relatively small sample size $(n=14)$, which can raise questions of reliability; however, the results were highly consistent across several analytic techniques. When taken together, the findings challenge long-standing interpretations regarding the mapping between a brain region and a fundamental cognitive function and, moreover, suggest serious caution when interpreting the function of neural regions involved during standard oldness judgments (Paller et al., 2007). Just as fluency might be misinterpreted as a memory signal, fluency-related PRC responses might be misinterpreted as memory-related activation patterns.

These results speak to why fluency so reliably affects recognition decisions. The cognitive psychology literature has long hypothesized that familiarity and fluency are interrelated, although the nature of their relationship has been intensely debated (Yonelinas, 2002). Surprisingly, this distinction has received little attention from fMRI studies (for review, see Dew and Cabeza, 2011). Although the current data do not counter the notion that familiarity can stem from nonfluency-derived sources (e.g., objective LTM traces), the data emphasize attributional accounts, whereby the memory experience arises from multiple, separable cues (for similar conclusions from ERP studies, see Woollams et al., 2008; Lucas et al., 2012). It has been theorized that fluency-driven illusory recognition occurs because previous experience facilitates later perception (Jacoby and Dallas, 1981; Westerman et al., 2003). Thus, under normal circumstances, relative fluency is a veritable cue for recognition and may also be fed forward as a cue for other subjective cognitive experiences. This experience-driven sensitivity to relative fluency, as a proxy for frequency, also brings to the forefront a broader literature on how readily the human mind detects statistical regularities in the environment (Turk-Browne et al., 2009).

As indicated previously, the standard model of PRC contributions to recognition memory (Fig. $5 A$ ) is that LTM retrieval leads to PRC reductions, which in turn lead to the increase in old responding. Our findings cannot be explained by this model because the changes in PRC and old responding occurred on new items, which contain little to no objective LTM. To account for our findings, we propose the expanded PRC model in Figure 5B. The effects observed during new trials correspond to the lower pathway of the expanded model: manipulations that increase fluency may lead to reduced PRC activity and to increases in old responses independently of LTM retrieval. It should be noted that, although not depicted in the model, a direct pathway from LTM retrieval to decreased PRC activity is also a possibility. In such a case, fluency and LTM retrieval would be independent contributors to PRC reductions. Although the focus of the current study was to investigate fluency without memory, future studies should probe this possibility by investigating memory without fluency. An important implication of the expanded model is that PRC may contribute not only to memory judgments but also other non-memory judgments influenced by fluency. Behavioral studies have shown that fluency produces an overwhelmingly consistent effect on a wide range of inferential decisions, from esthetic pleasure (Reber et al., 2004), to truth (Hansen et al., 2007), frequency (Kahneman and Tversky, 1973), and even art appreciation (Belke et al., 2010). Given this uniformity, it has been proposed recently that there may be a common mechanism underlying the diverse effects of fluency on judgment (Alter and Oppenheimer, 2009). The expanded model proposes a broader view of PRC function, with the intention of providing a closer link with prevailing cognitive theory. One caveat is that the model does not account for other brain regions that may be linked with processing fluency, including non-PRC regions identified by the fluency $X$ response interaction. Another caveat is that the study only tests the effects of fluency on memory decisions; thus, the link to non-memory decisions is speculative. That said, the goal of the proposed model is not only to account for the current findings but also to spawn new hypotheses and lines of future research on the neural mechanisms of fluency and its influence on social and cognitive decisions.

One open question is whether the observed effect reflects a generalized fluency mechanism or is specific to semantic fluency. A sensitivity of PRC to semantic fluency fits with evidence linking the anterior temporal lobes to semantic representations and processes (Nobre and McCarthy, 1995; Visser et al., 2010). A small number of studies have also linked the PRC with conceptual implicit memory, a nonconscious form of LTM retrieval in which performance on a cognitive task (e.g., generating category exemplars) is facilitated for studied relative to novel stimuli. One study showed PRC reductions during repeated relative to novel semantic decisions (O'Kane et al., 2005), and another linked PRC reductions with the magnitude of conceptual priming (Voss et al., 2009). In addition to retrieval-related deactivations, encodingrelated activations in PRC predict later conceptual priming (Wang et al., 2010). It is worth noting that, although tests of conceptual implicit memory measure task facilitation in a fluency-related manner, they do not disentangle fluency from oldness; thus, the contribution of PRC to fluency independently from LTM retrieval cannot be determined from these previous studies. The present data suggest that what accounts for a seemingly common role of PRC in recognition memory and concep- 
tual implicit memory may be semantic fluency rather than LTM. More generally, these results are consistent with the idea that the PRC is connected to an anterior brain network beyond the memory domain (Ranganath and Ritchey, 2012).

Notably, other evidence has linked PRC to nonsemantic operations, such as object perception and visual discrimination. The perceptual-mnemonic/feature-conjunction model, which posits that the PRC contributes to perception via the visual objectanalyzer pathway, has been supported by perirhinal lesion studies in monkeys showing that impairment on visual discrimination tasks increases with greater feature ambiguity (Murray et al., 2007). In fMRI studies in humans, detection of visual object change has been associated with right PRC activity (Lee et al., 2006), and the PRC has been shown to distinguish between accurate and inaccurate perceptual oddball judgments (O'Neil et al., 2009). An interesting possibility is that the mechanism underlying a common role of PRC in semantic and visual processing is fluency. Evidence supporting this possibility is the fluencyrelated perirhinal connectivity with visual cortex. This finding is consistent with the predictive interactive multiple memory systems model (Henson and Gagnepain, 2010), which proposes that semantic predictive coding from PRC modulates perceptual processing in occipito-temporal cortex. As such, although the current data indicate a contribution of PRC to semantic fluency specifically, they are not mutually exclusive with evidence that PRC lesions impair perceptual processing.

In conclusion, the present study is the first to establish a direct link between PRC and memory misattributions derived from fluency. The data support a model of PRC function whereby fluency mediates the relationship between the PRC and recognition decisions. Finally, the data motivate a broader decision model to be tested in future research. As depicted in Figure $5 B$, an implication of the data is that we should expect PRC deactivations during non-memory decisions derived from fluency, ranging from favorability to likelihood of truth. Investigating this question will work toward providing a more comprehensive picture of the function of the PRC both within and beyond the realm of memory, as well as how and why a process as basic as fluency so pervasively influences our cognitive experiences.

\section{References}

Alter AL, Oppenheimer DM (2009) Uniting the tribes of fluency to form a metacognitive nation. Pers Soc Psychol Rev 13:219-235. CrossRef Medline

Belke B, Leder H, Strobach T, Carbon CC (2010) Cognitive fluency: highlevel processing dynamics in art appreciation. Psychol Aesthet Creat Arts 4:214-222. CrossRef

Brown MW, Aggleton JP (2001) Recognition memory: what are the roles of the perirhinal cortex and hippocampus? Nat Rev Neurosci 2:51-61. CrossRef Medline

Brown MW, Xiang JZ (1998) Recognition memory: neuronal substrates of the judgement of prior occurrence. Prog Neurobiol 55:149-189. CrossRef Medline

Buckner RL, Wheeler ME (2001) The cognitive neuroscience of remembering. Nat Rev Neurosci 2:624-634. CrossRef Medline

Clark RE, Squire LR (2010) An animal model of recognition memory and medial temporal lobe amnesia: history and current issues. Neuropsychologia 48:2234-2244. CrossRef Medline

Daselaar SM, Fleck MS, Cabeza R (2006) Triple dissociation in the medial temporal lobes: recollection, familiarity, and novelty. J Neurophysiol 96: 1902-1911. CrossRef Medline

Desimone R (1996) Neural mechanisms for visual memory and their role in attention. Proc Natl Acad Sci U S A 93:13494-13499. CrossRef Medline

Devlin JT, Price CJ (2007) Perirhinal contributions to human visual perception. Curr Biol 17:1484-1488. CrossRef Medline

Dew IT, Cabeza R (2011) The porous boundaries between explicit and im- plicit memory: behavioral and neural evidence. Ann N Y Acad Sci 1224: 174-190. CrossRef Medline

Dobbins IG, Rice HJ, Wagner AD, Schacter DL (2003) Memory orientation and success: separable neurocognitive components underlying episodic recognition. Neuropsychologia 41:318-333. CrossRef Medline

Eichenbaum H, Yonelinas AP, Ranganath C (2007) The medial temporal lobe and recognition memory. Annu Rev Neurosci 30:123-152. CrossRef Medline

Glover GH, Law CS (2001) Spiral-in/out BOLD fMRI for increased SNR and reduced susceptibility artifacts. Magn Reson Med 46:515-522. CrossRef Medline

Gonsalves BD, Kahn I, Curran T, Norman KA, Wagner AD (2005) Memory strength and repetition suppression: multimodal imaging of medial temporal cortical contributions to recognition. Neuron 47:751-761. CrossRef Medline

Hansen J, Dechene A, Wanke M (2007) Discrepant fluency increases subjective truth. J Exp Social Psychol 44:687-691.

Henson RN, Gagnepain P (2010) Predictive, interactive multiple memory systems. Hippocampus 20:1315-1326. CrossRef Medline

Henson RN, Shallice T, Dolan RJ (1999) Right prefrontal cortex and episodic memory retrieval: a functional MRI test of the monitoring hypothesis. Brain 122:1367-1381. CrossRef Medline

Henson RN, Cansino S, Herron JE, Robb WG, Rugg MD (2003) A familiarity signal in human anterior medial temporal cortex? Hippocampus 13: 301-304. CrossRef Medline

Jacoby LL, Dallas M (1981) On the relationship between autobiographical memory and perceptual learning. J Exp Psychol Gen 110:306-340. CrossRef Medline

Jacoby LL, Whitehouse K (1989) An illusion of memory: False recognition influenced by unconscious perception. J Exp Psychol Gen 118:126-135. CrossRef

Kahneman D, Tversky A (1973) Psychology of prediction. Psychol Rev 80: 237-251. CrossRef

Kucera H, Francis WN (1967) Computational analysis of present-day American English. Providence, RI: Brown UP.

Kurilla BP, Westerman DL (2008) Processing fluency affects subjective claims of recollection. Mem Cognit 36:82-92. CrossRef Medline

Lee AC, Bandelow S, Schwarzbauer C, Henson RN, Graham KS (2006) Perirhinal cortex activity during visual object discrimination: an eventrelated fMRI study. Neuroimage 33:362-373. CrossRef Medline

Lucas HD, Taylor JR, Henson RN, Paller KA (2012) Many roads lead to recognition: electrophysiological correlates of familiarity derived from short-term masked repetition priming. Neuropsychologia 50:3041-3052. CrossRef Medline

Macmillan NA, Creelman CD (2005) Detection theory. New York: Erlbaum.

Meunier M, Bachevalier J, Mishkin M, Murray EA (1993) Effects on visual recognition of combined and separate ablations of the entorhinal and perirhinal cortex in rhesus-monkeys. J Neurosci 13:5418-5432. Medline

Montaldi D, Spencer TJ, Roberts N, Mayes AR (2006) The neural system that mediates familiarity memory. Hippocampus 16:504-520. CrossRef Medline

Mumby DG, Pinel JP (1994) Rhinal cortex lesions and object recognition in rats. Behav Neurosci 108:11-18. CrossRef Medline

Murray EA, Bussey TJ, Saksida LM (2007) Visual perception and memory: a new view of medial temporal lobe function in primates and rodents. Annu Rev Neurosci 30:99-122. CrossRef Medline

Nelson DL, McEvoy CL, Schreiber TA (2004) The University of South Florida free association, rhyme, and word fragment norms. Behav Res Methods Instrum Comput 36:402-407. CrossRef Medline

Nobre AC, McCarthy G (1995) Language-related field potentials in the anterior-medial temporal lobe. II. Effects of word type and semantic priming. J Neurosci 15:1090-1098. Medline

Nolde SF, Johnson MK, Raye CL (1998) The role of prefrontal cortex during tests of episodic memory. Trends Cogn Sci 2:399-406. CrossRef Medline

O'Kane G, Insler RZ, Wagner AD (2005) Conceptual and perceptual novelty effects in human medial temporal cortex. Hippocampus 15:326-332. CrossRef Medline

O’Neil EB, Cate AD, Köhler S (2009) Perirhinal cortex contributes to accuracy in recognition memory and perceptual discriminations. J Neurosci 29:8329-8334. CrossRef Medline

Paller KA, Voss JL, Boehm SG (2007) Validating neural correlates of familiarity. Trends Cogn Sci 11:243-250. CrossRef Medline 
Rajaram S, Geraci L (2000) Conceptual fluency selectively influences knowing. J Exp Psychol Learn Mem Cogn 26:1070-1074. CrossRef Medline

Ranganath C, Ritchey M (2012) Two cortical systems for memory-guided behaviour. Nat Rev Neurosci 13:713-726. CrossRef Medline

Reber R, Schwarz N, Winkielman P (2004) Processing fluency and aesthetic pleasure: Is beauty in the perceiver's processing experience? Pers Soc Psychol Rev 8:364-382. CrossRef Medline

Rissman J, Gazzaley A, D’Esposito M (2004) Measuring functional connectivity during distinct stages of a cognitive task. Neuroimage 23: 752-763. CrossRef Medline

Stark CE, Squire LR (2001) Simple and associative recognition memory in the hippocampal region. Learn Mem 8:190-197. CrossRef Medline

Suzuki WA, Zola-Morgan S, Squire LR, Amaral DG (1993) Lesions of the perirhinal and parahippocampal cortices in the monkey produce longlasting memory impairment in the visual and tactual modalities. J Neurosci 13:2430-2451. Medline

Taylor JR, Henson RN (2012) Could masked conceptual primes increase recollection? The subtleties of measuring recollection and familiarity in recognition memory. Neuropsychologia 50:3027-3040. CrossRef Medline

Taylor JR, Buratto LG, Henson RN (2013) Behavioral and neural evidence for masked conceptual priming of recollection. Cortex 49:1511-1525. CrossRef Medline

Turk-Browne NB, Scholl BJ, Chun MM, Johnson MK (2009) Neural evidence of statistical learning: efficient detection of visual regularities without awareness. J Cogn Neurosci 21:1934-1945. CrossRef Medline
Visser M, Jefferies E, Lambon Ralph MA (2010) Semantic processing in the anterior temporal lobes: a meta-analysis of the functional neuroimaging literature. J Cogn Neurosci 22:1083-1094. CrossRef Medline

Voss JL, Hauner KK, Paller KA (2009) Establishing a relationship between activity reduction in human perirhinal cortex and priming. Hippocampus 19:773-778. CrossRef Medline

Wang WC, Lazzara MM, Ranganath C, Knight RT, Yonelinas AP (2010) The medial temporal lobe supports conceptual implicit memory. Neuron 68:835-842. CrossRef Medline

Westerman DL (2008) Relative fluency and illusions of recognition memory. Psychon Bull Rev 15:1196-1200. CrossRef Medline

Westerman DL, Miller JK, Lloyd ME (2003) Change in perceptual form attenuates the use of the fluency heuristic in recognition. Mem Cognit 31:619-629. CrossRef Medline

Whittlesea BW, Williams LD (2001) The discrepancy-attribution hypothesis. I. The heuristic basis of feelings of familiarity. J Exp Psychol Learn Mem Cogn 27:3-13. CrossRef Medline

Whittlesea BW, Jacoby LL, Girard K (1990) Illusions of immediate memory: evidence of an attributional basis for feelings of familiarity and perceptual quality. J Mem Lang 29:716-732. CrossRef

Woollams AM, Taylor JR, Karayanidis F, Henson RN (2008) Eventrelated potentials associated with masked priming of test cues reveal multiple potential contributions to recognition memory. J Cogn Neurosci 20:1114-1129. CrossRef Medline

Yonelinas AP (2002) The nature of recollection and familiarity: a review of 30 years of research. J Mem Lang 46:441-517. CrossRef 